\title{
On Starlikeness of Libera Transform
}

(Jelmaan Libera Seperti Bintang)

\author{
MAMORU NUNOKAWA \& JANUSZ SOKÓŁ*
}

\section{ABSTRACT}

Let $A$ denote the class of functions $f$ that are analytic in the unit disc $D$ and normalized by $f(0)=f^{\prime}(0)-1=0$. In this paper conditions are determined for starlikeness of the Libera integral of functions such that $\left|\arg \left\{f^{\prime}\right\}\right|<\delta$ in $D$. The results of Miller and Mocanu (2002) on Libera transform of functions with bounded turning are improved.

Keywords: Nunokawa's lemma; starlike functions; strongly starlike functions

\section{ABSTRAK}

Biarkan A menandakan kelas fungsif yang analitik dalam cakera unit D dan dinormalkan oleh $f(0)=f^{\prime}(0)-1=0$. Dalam kertas ini keadaan ditentukan untuk fungsi kamiran Libera seperti bintang adalah $\left|\arg \left\{f^{\prime}\right\}\right|<\delta$ dalam D. Keputusan Miller dan Mocanu (2002) atas transformasi fungsi Libera dengan pusingan terbatas bertambah baik.

Kata kunci: Fungsi seperti bintang; fungsi seperti bintang yang kuat; lema Nunokawa

\section{INTRODUCTION}

Let $H$ be the class of functions analytic in the unit disk $D$ $=\{z \in C:|z|<1\}$, and denote by $A_{n}$ the class of functions $f \in H$ with the normalization of the form:

$$
f(z)=z+a_{n+1} z^{n+1}+a_{n+2} z^{n+2}+\ldots z \in D
$$

with $A_{1}=A$. Let $S S^{*}(\beta)$ denote the class of strongly starlike functions of order $\beta, 0<\beta \leq 1$,

$$
S S^{*}(\beta)=\left\{f \in A:\left|\arg \frac{z f^{\prime}(z)}{f(z)}\right|<\frac{\beta \pi}{2}, z \in D\right\},
$$

which was introduced in Stankiewicz (1966) and Brannan and Kirwan (1969). The class $S_{\alpha}^{*}$ of starlike functions of order $\alpha<1$ defined by:

$$
S_{\alpha}^{*}=\left\{f \in A: \operatorname{Re} \frac{z f^{\prime}(z)}{f(z)}>\alpha, z \in D\right\},
$$

was introduced by Robertson (2008). We have $S S^{*}(1)=$ $S_{0}^{*}=S^{*}$, where $S^{*}$ is the class of functions $f \in A$ such that $f(D)$ is a starlike set with respect to the origin. Functions in the class

$$
R=\left\{f \in A: \operatorname{Re}\left\{f^{\prime}(z)\right\}>0, z \in D\right\},
$$

are called functions with bounded turning. The Libera transform $L: A \rightarrow A, L[f]=F$, where:

$$
F(z)=\int_{0}^{z} f(t) \mathrm{d} t
$$

is the Libera integral operator, which has been studied by several authors on different counts. Mocanu (1986) considered the problem of starlikeness and proved the following result.

Theorem 1.1. (Mocanu 1986) If $f(z)$ is analytic and $\mathrm{Re}$ $\left\{f^{\prime}(z)\right\}>0$ in the unit $\operatorname{disc} D$ and if the function $F$ is given by (1.1), then $F \in S^{*}$.

This result may be written shortly as follows.

$$
L[R] \subset S^{*}=S S^{*}(1)
$$

where $L[R]=\{L[f]: f \in R\}$. Mocanu (1995) improved (1.2) by showing that

$$
L[R] \subset S S^{*}(8 / 9)
$$

Miller and Mocanu (2002) showed that subcase of this last result can be sharpened to:

$$
L\left[R \cap A_{2}\right] \subset S S^{*}(2 / 3) .
$$

The problem of strongly starlikeness of $L[f]$ for $f \in R$ was also considered in Sokół, (2008) where it was shown that

$$
L\left[R \cap A_{2}\right] \subset S S^{*}(3 / 5) .
$$

The above inclusion relationship is equivalent to the following differential implication:

$$
f \in A_{2} \text { and } \operatorname{Re}\left\{f^{\prime}(z)\right\}>0 \Rightarrow\left|\arg \frac{z F^{\prime}(z)}{F(z)}\right|<\frac{3 \pi}{10},
$$


or equivalently:

$$
f \in A_{2} \text { and } \operatorname{Re}\left\{F^{\prime}(z)+\frac{1}{2} F^{\prime \prime}(z)\right\}>0 \Rightarrow\left|\arg \frac{z F^{\prime}(z)}{F(z)}\right|<\frac{3 \pi}{10},
$$

where $F$ is given by (1.1).

The Mocanu's result (1.3) was improved in two manners (Nunokawa et al. in press).

Theorem 1.2. (Nunokawa et al. in press) If $f(z) \in A$ and $\operatorname{Re}\left\{f^{\prime}(z)\right\}>0$ in the unit disc $D$, then the function (1.1) satisfies

$$
\left|\arg \frac{z f^{\prime}(z)}{f(z)}\right|<\frac{\alpha \pi}{2}=1.368 \ldots, \quad z \in D,
$$

where

$$
\alpha=\frac{2}{\pi}\left(\frac{\pi}{2}-\log 2\right)\left(1+\frac{\pi}{2}-\log 2\right)=0.870907 \ldots .
$$

Theorem 1.3. (Nunokawa et al. in press) Iff $(z) \in A$ and $\left|\arg \left\{f^{\prime}(z)\right\}\right|<\gamma \pi / 2$ in the unit disc $D$, then the function (1.1) satisfies

$$
\operatorname{Re}\left\{\frac{z F^{\prime}(z)}{F(z)}\right\}>0, \quad z \in D,
$$

where

$$
\gamma=\frac{\pi^{2}}{(\pi-\log 2)(2 \pi-\log 4)}=1.14823 \ldots .
$$

Theorem 1.2 may be written as

$$
L[R] \subset S S^{*}(\alpha) .
$$

where $\alpha$ is given in (1.5) satisfies $\alpha<8 / 9=0.888 \ldots$ which shows that the result (1.7) is the small improvement of (1.3).

In (Nunokawa et al. in press) were also obtained the following results for the related integral operator

$$
\hat{F}(z)=\int_{0}^{z} \frac{f(t)}{t} \mathrm{dt}
$$

Theorem 1.4. (Nunokawa et al. in press) If $f(z) \in A$ and $\operatorname{Re}\left\{f^{\prime}(z)\right\}>0$ in the unit disc $D$, then the function (1.8) satisfies

$$
\left|\arg \frac{z F^{\prime}(z)}{F(z)}\right|<\frac{\alpha \pi}{2}=1.368 \ldots, \quad z \in D,
$$

Where $\alpha$ is the solution of the equation

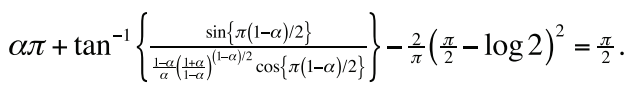

Theorem 1.5. (Nunokawa et al. in press) If $f(z) \in A$ and $\left|\arg \left\{f^{\prime}(z)\right\}\right|<\gamma \pi / 2$ in the unit disc $D$, then the function (1.8) satisfies

$$
\operatorname{Re}\left\{\frac{z \hat{F}^{\prime}(z)}{\hat{F}(z)}\right\}>0, \quad z \in D,
$$

where

$$
\gamma=1 /\left(1+(\pi / 2-\log 2)^{2} / 4\right)=0.762 \ldots .
$$

\section{MAIN RESULT}

In this paper we go back to the problem of starlikeness of Libera transform. The key for the improvement previous results is the following theorem and very often applied Nunokawa’s lemma (Nunokawa 1993).

Theorem 2.1. Let $p(z)$ be analytic in $D$ with $p(0)=1$ and suppose that

$$
p(z)+z p^{\prime}(z) \prec\left(\frac{1+z}{1-z}\right)^{\alpha}, \quad z \in D,
$$

where $0<\alpha<2$ and $\gamma$. Then we have

$$
p(z) \prec\left(\frac{1+z}{1-z}\right)^{\beta}, \quad z \in D,
$$

where $\beta=\alpha(1-(2 / \pi) \log 2)$.

Proof. From the hypothesis, we have

$$
\begin{aligned}
\gamma p(z) & =\frac{\gamma p(z) z^{\frac{1}{\gamma}}}{z^{1 / \gamma}}=\frac{1}{z^{1 / \gamma}} \int_{0}^{z} \gamma\left\{\frac{t^{1 / \gamma} p(t)}{\gamma}+t^{1 / \gamma p^{\prime}(t)}\right\} d t \\
& =\frac{1}{z^{1 / \gamma}} \int_{0}^{z} t^{\frac{1}{\gamma}-1}\left\{p(t)+\gamma t p^{\prime}(t)\right\} d t \\
& =\frac{1}{r^{1 / \gamma}} \int_{0}^{r} \rho^{\frac{1}{\gamma}-1}\left\{p\left(\rho e^{i \theta}\right)+\gamma \rho e^{i \theta} p^{\prime}\left(\rho e^{i \theta}\right)\right\} d \rho,
\end{aligned}
$$

where $z=r e^{i \theta}, t=\rho e^{i \theta}$ and $0 \leq \rho \leq r$. Then by (2.1), we have

$$
\begin{aligned}
|\arg \{p(z)\}|=|\arg \{\gamma p(z)\}|=\mid \arg \left\{\frac{1}{r^{1 / \gamma}} \int_{0}^{r} \rho^{\frac{1}{\gamma}-1}\left\{p\left(\rho e^{i \theta}\right)+\gamma \rho e^{i \theta} p^{\prime}\left(\rho e^{i \theta}\right)\right\} d \rho\right\} \\
=\mid \arg \left\{\int_{0}^{r} \rho^{\frac{1}{\gamma}-1}\left\{p\left(\rho e^{i \theta}\right)+\gamma \rho e^{i \theta} p^{\prime}\left(\rho e^{i \theta}\right)\right\} d \rho\right\} \\
\quad \leq \int_{0}^{r}\left|\arg \left\{p\left(\rho e^{i \theta}\right)+\gamma \rho e^{i \theta} p^{\prime}\left(\rho e^{i \theta}\right)\right\}\right| d \rho \\
=\int_{0}^{r} \alpha\left|\arg \left\{p\left(\rho e^{i \theta}\right)+\gamma \rho e^{i \theta} p^{\prime}\left(\rho e^{i \theta}\right)\right\}^{1 / \alpha}\right| d \rho \\
\quad \leq \int_{0}^{r} \alpha\left|\arg \frac{1+\rho e^{i \theta}}{1-\rho e^{i \theta}}\right| d \rho .
\end{aligned}
$$

The function $w(z)=(1+z) /(1-z)$ is univalent in $D$ and maps $|z|<\rho<1$ onto the open disc $D(C, R)$ with the center $C=\left(1+\rho^{2}\right) /\left(1-\rho^{2}\right)$ and the radius $R=(2 \rho) /\left(1-\rho^{2}\right)$. A simple geometric observation yields to

$$
\left|\arg \frac{1+\rho e^{i \theta}}{1-\rho e^{i \theta}}\right| \leq \sin ^{-1} \frac{R}{C}=\sin ^{-1} \frac{2 \rho}{1-\rho^{2}} \text {, for all } \rho \in[0,1) .
$$


Therefore, we obtain

$$
\begin{aligned}
& |\arg \{p(z)\}| \leq \int_{0}^{r} \alpha \sin ^{-1} \frac{2 \rho}{1-\rho^{2}} d \rho \\
& \leq \int_{0}^{1} \alpha \sin ^{-1} \frac{2 \rho}{1-\rho^{2}} d \rho \\
& =\alpha\left(\frac{\pi}{2}-\log 2\right) .
\end{aligned}
$$

This shows that

$$
p(z) \prec\left(\frac{1+z}{1-z}\right)^{\alpha(1-(2 / \pi) \log 2)}, z \in D,
$$

and it completes the proof.

Lemma 2.2. (Nunokawa 1993) Let $p(z)$ be of the form

$$
p(z)=1+\sum_{n=m \geq 1}^{\infty} a_{n} z^{n}, a_{m} \neq 1,
$$

with $p(z) \neq 0$ in D. If there exists a point $z_{0},\left|z_{0}\right|<1$, such that

$$
|\arg \{p(z)\}|<\alpha \pi / 2 \text { in }|z|<\left|z_{0}\right|
$$

and

$$
\left|\arg \left\{p\left(z_{0}\right)\right\}\right|=\alpha \pi / 2
$$

for some $\alpha>0$, then we have

$$
\frac{z_{0} p^{\prime}\left(z_{0}\right)}{p\left(z_{0}\right)}=i k \alpha
$$

where

$$
k \geq \frac{m\left(a^{2}+1\right)}{2 a} \text { when } \arg \left\{p\left(z_{0}\right)\right\}=\alpha \pi / 2,
$$

and

$$
k \leq-\frac{m\left(a^{2}+1\right)}{2 a} \text { when } \arg \left\{p\left(z_{0}\right)\right\}=-\alpha \pi / 2
$$

where

$$
\left\{p\left(z_{0}\right)\right\}^{1 / \alpha}=\mp i a, a>0 .
$$

Lemma 2.3. If $f(z) \in A$ and $\left|\arg \left\{f^{\prime}(z)\right\}\right|<\delta \pi / 2$ in the unit disc $D$, then the function (1.1) satisfies

$$
\left|\arg \left\{\frac{F(z)}{z}\right\}\right|<\delta\left(1-\left(\frac{2}{\pi}\right) \log 2\right)^{2} \pi / 2, \quad z \in D
$$

Proof. From (1.1) we obtain

$$
z F^{\prime \prime}(z)+2 F^{\prime}(z)=2 f^{\prime}(z)
$$

so we have $\left|\arg \left\{z F^{\prime \prime}(z)+2 F^{\prime}(z)\right\}\right|<\delta \pi / 2$. Therefore, by Theorem 2.1

$$
z F^{\prime \prime}(z)+2 F^{\prime}(z) \prec\left(\frac{1+z}{1-z}\right)^{\delta} \Rightarrow F^{\prime}(z) \prec\left(\frac{1+z}{1-z}\right)^{\varepsilon},
$$

where $\varepsilon=\delta(1-(2 / \pi) \log 2)$.

Further, let $p(z)=F(z) / z$. Then

$$
z p^{\prime}(z)+p(z)=F^{\prime}(z)
$$

so we have $\left|\arg \left\{z p^{\prime}(z)+p(z)\right\}\right|<\varepsilon \pi / 2$. Again, by Theorem 2.1 we obtain

$$
z p^{\prime}(z)+p(z) \prec\left(\frac{1+z}{1-z}\right)^{\varepsilon} \Rightarrow p(z) \prec\left(\frac{1+z}{1-z}\right)^{\theta}
$$

where $\theta=\varepsilon(1-(2 / \pi) \log 2)=\delta\{(1-(2 / \pi) \log 2)\}^{2}$ hence

$$
|\arg \{F(z) / z\}|<\delta\{(1-(2 / \pi) \log 2)\}^{2} \pi / 2 .
$$

Theorem 2.4. If $f(z) \in A$ and

$$
\left|\arg \left\{f^{\prime}(z)\right\}\right|<\delta \pi / 2,
$$

in the unit disc $D$, were

$$
\delta=\frac{5 \pi^{2}}{3\left\{\pi^{2}+\{\pi-\log 4\}^{2}\right\}}=1.270153 \ldots
$$

then the function (1.1) satisfies

$$
\operatorname{Re}\left\{\frac{z F^{\prime}(z)}{F(z)}\right\}>0, z \in D
$$

Proof. If there exists a point $z_{0},\left|z_{0}\right|<1$, such that

$$
\left|\arg \left\{\frac{z F^{\prime}(z)}{F(z)}\right\}\right|<\frac{\pi}{2} \quad\left(|z|<\left|z_{0}\right|\right)
$$

and

$$
\left|\arg \left\{\frac{z_{0} F^{\prime}\left(z_{0}\right)}{F\left(z_{0}\right)}\right\}\right|=\frac{\pi}{2}, p\left(z_{0}\right)= \pm i a, \quad 0<a,
$$

then from Lemma 2.2, we have (for brevity denote $\left.z F^{\prime}(z) / F(z)=p(z)\right)$

$$
\frac{z_{0} p^{\prime}\left(z_{0}\right)}{p\left(z_{0}\right)}=i k
$$

where

$$
k \geq \frac{a^{2}+1}{2 a} \geq 1 \quad \text { when } \arg \left\{p\left(z_{0}\right)\right\}=\pi / 2,
$$

and 
$k \leq \frac{a^{2}+1}{2 a} \leq-1$ when $\arg \left\{p\left(z_{0}\right)\right\}=-\pi / 2$,

For the case $\arg \left\{\frac{z F^{\prime}(z)}{F(z)}\right\}=\pi / 2$, we have

$\pi / 3<\arg \{1+i a+i k\}<\pi / 2$.

Moreover, by Lemma $2.3\left|\arg \left\{F\left(z_{0}\right) / z_{0}\right\}\right|<\delta\{(1-(2 / \pi)$ $\log 2)\}^{2} / 2$. Therefore, by some calculations we obtain

$$
\begin{aligned}
& \left|\arg \left\{F\left(z_{0}\right) / z_{0}\right\}\right|<\delta\{(1-(2 / \pi) \log 2)\}^{2} / 2 \\
= & \frac{5 \pi^{2}}{3\left\{\pi^{2}+\{\pi-\log 4\}^{2}\right\}}\{(1-(2 / \pi) \log 2)\}^{2} / 2 \\
= & \frac{5 \pi}{6}-\frac{\delta \pi}{2} .
\end{aligned}
$$

By (2.14), (2.15) and (2.16) we can write

$$
\begin{aligned}
& \left|\arg \left\{2 f^{\prime}\left(z_{0}\right)\right\}\right| \\
= & \left|\arg \left\{2 F^{\prime}\left(z_{0}\right)+z_{0} F^{\prime \prime}\left(z_{0}\right)\right\}\right| \\
= & \mid \arg \left\{\left\{\frac{z_{0} F^{\prime}\left(z_{0}\right)}{F\left(z_{0}\right)}\left(1+\frac{z_{0} F^{\prime}\left(z_{0}\right)}{F\left(z_{0}\right)}+\frac{z_{0} p^{\prime}\left(z_{0}\right)}{p\left(z_{0}\right)}\right) \frac{F\left(z_{0}\right)}{z_{0}}\right\}\right. \\
= & \left|\arg \left\{\frac{z_{0} F^{\prime}\left(z_{0}\right)}{F\left(z_{0}\right)}(1+i a+i k) \frac{F\left(z_{0}\right)}{z_{0}}\right\}\right| \\
& \geq \frac{\pi}{2}+\frac{\pi}{3}-\left(\frac{2 \pi}{6}-\frac{\delta \pi}{2}\right) \\
= & \frac{\delta \pi}{2} .
\end{aligned}
$$

It contradicts hypothesis (2.11) and for the case $\arg \left\{\frac{z F^{\prime}(z)}{F(z)}\right\}=-\pi / 2$, applying the same method as the above, we also have (2.17). It is also the contradiction and it completes the proof.

Let us denote for $\delta \in R$ the class

$$
R(\delta)=\left\{f \in A:\left|\arg \left\{f^{\prime}(z)\right\}\right|<\delta \pi / 2, \quad z \in D\right\} .
$$

Theorem 2.4 is an improvement of Mocanu's result (1.2) so we express it in the following corollary.

\section{Corollary 2.5. If}

$$
\delta \leq \frac{5 \pi^{2}}{3\left\{\pi^{2}+\{\pi-\log 4\}^{2}\right\}}=1.270153 \ldots
$$

then

$$
L[R(\delta)] \subset S^{*}=S S^{*}(1)
$$

In Mocanu's result (1.2) was 1 instead of 1.270153. ... obtained here. The best possible constant is not established yet. We put the following conjecture.

\section{Conjecture}

$$
L[R(\pi / 2)] \subset S^{*}=S S^{*}(1) .
$$

\section{REFERENCES}

Brannan, D.A. \& Kirwan, W.E. 1969. On some classes of bounded univalent functions. J. London Math. Soc. 1(2): 431-443.

Miller, S.S. \& Mocanu, P.T. 2002. Libera transform of functions with bounded turning. J. Math. Anal. Appl. 276: 90-97.

Mocanu, P.T. 1995. New extensions of a theorem of R. Singh and S. Singh. Mathematica (Cluj) 37(60): 171-182.

Mocanu, P.T. 1986. On starlikness of Libera transform. Mathematica (Cluj) 28(51): 153-155.

Nunokawa, M. 1993. On the order of strongly starlikeness of strongly convex functions. Proc. Japan Acad. 69 (Ser. A): 234-237.

Nunokawa, M., Cho, N.E., Kwon, O.S. \& Sokół, J. On extensions of Mocanu's P.T. results, submitted for publication.

Robertson, M.S. 1936. On the theory of univalent functions. Ann. Math. 37: 374-408.

Sokół, J. 2008. Starlikeness of the Libera transform of functions with bounded turning. Appl. Math. Comput. 203: 273-276.

Stankiewicz, J. 1966. Quelques problemes extremaux dans les classes des fonctions -angulairement etoiles. Ann. Univ. Mariae Curie-Skłodowska, Sect. A 20: 59-75.

\section{Mamoru Nunokawa}

University of Gunma, Hoshikuki-cho 798-8

Chuou-Ward, Chiba 260-0808

Japan

Janusz Sokół*

Department of Mathematics

Rzeszów University of Technology,

Al. Powstańców Warszawy 12, 35-959 Rzeszów

Poland

*Corresponding author; email: jsokol@prz.edu.pl

Received: 18 January 2014

Accepted: 15 March 2014 